\title{
Distal attachment device is mandatory for screening-related colonoscopy
}

\section{다 (요우}

\author{
Author \\ Conor Lahiff \\ Institution \\ Mater Misericordiae University Hospital, Dublin, Ireland \\ Bibliography \\ Endosc Int Open 2021; 09: E1593-E1594 \\ DOI 10.1055/a-1529-6021 \\ ISSN 2364-3722 \\ (c) 2021. The Author(s). \\ This is an open access article published by Thieme under the terms of the Creative \\ Commons Attribution-NonDerivative-NonCommercial License, permitting copying \\ and reproduction so long as the original work is given appropriate credit. Contents
}

\author{
may not be used for commercial purposes, or adapted, remixed, transformed or \\ built upon. (https://creativecommons.org/licenses/by-nc-nd/4.0/) \\ Georg Thieme Verlag KG, Rüdigerstraße 14, \\ 70469 Stuttgart, Germany \\ Corresponding author \\ Conor Lahiff, Mater Misericordiae University Hospital, \\ Gastrointestinal Unit, Whitty Building Level 4 Eccles Street, \\ Dublin 7, Ireland \\ conorlahiff@mater.ie
}

Cap-assisted colonoscopy first appeared in Japan in the $1990 \mathrm{~s}$ and since then, its use for diagnostic colonoscopy has been slowly gaining acceptance, supported by technical developments and new devices showing incremental benefit in terms of adenoma yield, an established surrogate for colorectal cancer-related mortality [1]. While the first-generation Endocuff has not been shown to be effective in this context [2] and aggregate gains from Endocuff-assisted colonoscopy (EAC) have been considered to be equivocal in comparison to standard colonoscopy (SC) [3] and transparent cap-assisted colonoscopy (TAC) $[4,5]$, recent high-quality evidence supports the utility of the next-generation Endocuff Vision (ECV, Olympus Japan) in the context of colon cancer screening $[6,7]$.

Endocuff Vision (ECV, Olympus Japan) is a single-use, add-on device that can be applied to the tip of a standard colonoscope. It has multiple finger-like protrusions that extend outside of the cap, are compressed on insertion of the colonoscope, and then open on withdrawal to facilitate exposure of mucosal folds during inspection.

In the current issue of EIO, Forbes et al. [8] present a realworld evaluation of ECV and its utility and uptake in an uncontrolled environment within a large screening-based colonoscopy practice in Canada. While any non-randomized study is open to risk of bias, this observational cohort study included a large sample and its results are broadly consistent with data from previous randomized controlled trials (RCTs). The authors employed several statistical approaches to minimize these limitations and their results are broadly consistent across the primary outcome (adenoma detection rate [ADR]) and a range of relevant secondary outcomes. Importantly, there appears to have been no adverse impact on procedure- and patient-related performance measures.

The study design related to a 1-year period in which ECV use in a single high-volume center was incorporated into daily practice, focusing on a selected cohort of screening-related indications for colonoscopy. The study considered two time periods: a baseline period during which ECV use was discretionary, followed by a 1-month training period (data not analyzed from this period) and then an ECV period, during which use of ECV was the default (caps applied by endoscopy unit staff in all cases) but remained at the discretion of the endoscopist (high uptake $>70 \%)$. The study included a high number of endoscopists (40 total, gastroenterologists and colorectal surgeons) with varying degrees of volume, subspecialty, and baseline ADRs.

While the use of ECV was associated with an increased likelihood of detecting at least one adenoma (AOR 1.24, CI 1.1-1.4), the likelihood of detecting sessile serrated lesions (SSLs) was not statistically significant (AOR 1.13, Cl 0.97-1.31) but did seem to improve in subgroup analyses (non-FIT positive). Further, the benefit in terms of ADR appears to be confined to polyps $<10 \mathrm{~mm}$. A propensity score analysis (ECV group only) did see a maintained benefit in terms of ADR and SSL detection rate, although with wider confidence intervals approaching unity in both subgroups.

Notwithstanding the benefit in terms of diagnostic yield, procedural parameters (cecal intubation, withdrawal times, procedure duration, sedation use, and patient comfort) were not affected adversely by ECV use. Removal of the ECV was required in $4.6 \%$ of cases, an acceptable level and predominantly in the left colon, thus presumably not affecting procedure 
times significantly for patients in whom ECV removal was necessary.

Existing data tell us that ADR varies widely among endoscopists and this point is highlighted by the authors in their discussion. While low-cost quality bundles [9] and cheaper adjuncts such as narrow-band imaging [10] are proven to improve $A D R$, widescale adoption of these measures can prove challenging outside of specialist settings [11]. Like any quality improvement intervention, the greatest benefit for ADR is expected by improving detection rates for low detectors, rather than adding small increments to endoscopists already performing at a high level. ECV further appears to improve ADR while reducing inspection times, suggesting more detection per unit time and potentially leading to enhanced efficiencies in endoscopy units.

We expect newer adjuncts, such as artificial intelligence (AI) detection software, to support ADR in general endoscopic practice in the near future. However, these tools are still limited by the level of mucosal exposure presented to them by the endoscopist. Mucosal exposure percentages are now quantifiable by Al software and are likely to become a relevant measure of quality for colonoscopy as Al systems become more widely applied. Due to its mechanism of action, ECV has the potential to increase mucosal exposure and it is, therefore, possible that the addition of simple adjuncts like ECV to traditional quality bundles and supported by Al systems will provide the optimal setup to ensure high-level ADRs across the next generation of endoscopists.

Other questions remain to be answered for ECV-assisted colonoscopy. Therapeutic procedures were not analyzed in this study and planned advanced polypectomy/EMRs were excluded. While this was done for valid reasons in line with the study design, it remains unknown if ECV is useful in a therapeutic setting, either in terms of shortening procedure time or improving technical/procedural outcomes. The authors did not present any data on ileal intubation, an area in which ECV may import some limitations, and it is likely due to the nature of the cohort (screening) and lack of clinical indication for ileal intubation. Finally, the role of ECV-assisted colonoscopy in supporting detection of SSLs remains unclear, although conclusions from RCT data guard against its application in surveillance of serrated polyposis syndrome [12]. ECV application may need to be considered carefully in a more diverse endoscopic practice than that presented in this study.

Given the consistent benefit for ECV in terms of ADR in RCTs and now supported by this well-designed, large, real-world cohort analysis, the established benefits of enhanced ADR in relation to reducing CRC mortality [1] and notwithstanding some remaining questions over advanced adenomas, ECV use across screening programs should prove cost-effective. Further study is clearly needed in this regard and is likely to be subject to jurisdiction with varying costs of ECV, colonoscopy tariffs, and sur- veillance guidelines, as shown in other cost-effectiveness studies for colonoscopy [13].

\section{Competing interests}

The authors declare that they have no conflict of interest.

\section{References}

[1] Corley DA, Jensen CD, Marks AR et al. Adenoma detection rate and risk of colorectal cancer and death. N Engl J Med 2014; 370: 12981306

[2] van Doorn SC, van der Vlugt M, Depla A et al. Adenoma detection with Endocuff colonoscopy versus conventional colonoscopy: a multicentre randomised controlled trial. Gut 2017; 66: 438-445

[3] Facciorusso A, Del Prete V, Buccino RV et al. Comparative efficacy of colonoscope distal attachment devices in increasing rates of adenoma detection: a network meta-analysis. Clin Gastroenterol Hepatol 2018; 16: 1209-1219

[4] Imaeda H, Yamaoka M, Ohgo H et al. Randomized control trial of adenoma detection rate in Endocuff-assisted colonoscopy versus transparent hood-assisted colonoscopy. J Gastroenterol Hepatol 2019; 34: 1492-1496

[5] Lahiff C, East JE. Distal attachments for adenoma detection go headto-head: Cap or cuff? J Gastroenterol Hepatol 2019; 34: 1471-1473

[6] Ngu WS, Bevan R, Tsiamoulos ZP et al. Improved adenoma detection with Endocuff Vision: the ADENOMA randomised controlled trial. Gut 2019; 68: 280-288

[7] Patel HK, Chandrasekar VT, Srinivasan S et al. Second-generation distal attachment cuff improves adenoma detection rate: meta-analysis of randomized controlled trials. Gastrointest Endosc 2021; 93: 544553

[8] Forbes N, Hillsden R], Ruan Y et al. Endocuff Vision improves adenoma detection rate in a large screening-related cohort. Endosc Int Open 2021; 09: E1583-E15920

[9] Rajasekhar PT, Rees C], Bramble MG et al. A multicenter pragmatic study of an evidence-based intervention to improve adenoma detection: the Quality Improvement in Colonoscopy (QIC) study. Endoscopy 2015; 47: 217-224

[10] Atkinson NSS, Ket S, Bassett P et al. Narrow-band imaging for detection of neoplasia at colonoscopy: a meta-analysis of data from individual patients in randomized controlled trials. Gastroenterology 2019; 157: 462-471

[11] Bisschops R, Rutter MD, Areia M et al. Overcoming the barriers to dissemination and implementation of quality measures for gastrointestinal endoscopy: European Society of Gastrointestinal Endoscopy (ESGE) and United European Gastroenterology (UEG) position statement. Endoscopy 2021; 53: 196-202

[12] Rivero-Sanchez L, Lopez Vicente J, Hernandez Villalba L et al. Endocuff-assisted colonoscopy for surveillance of serrated polyposis syndrome: a multicenter randomized controlled trial. Endoscopy 2019; 51: 637-645

[13] Mori Y, Kudo SE, East JE et al. Cost savings in colonoscopy with artificial intelligence-aided polyp diagnosis: an add-on analysis of a clinical trial (with video). Gastrointest Endosc 2020; 92: 905-911 